\title{
Luminal B is the Most Common Intrinsic Molecular Subtypes of Invasive Ductal Breast Carcinoma Patients in East Kalimantan, Indonesia
}

\author{
Swandari Paramita ${ }^{1,2 *}$, Eko Nugroho Raharjo ${ }^{3}$, Maria Niasari $^{3}$, Fieska Azizah $^{4}$, \\ Nur Ahlina Hanifah ${ }^{4}$
}

\begin{abstract}
Objective: Breast carcinoma has no longer been considered as a single and standalone disease. Its subtypes have been known to vary in terms of risk factors, natural histories, and responses to therapies. In particular, intrinsic molecular subtypes based on St. Gallen International Expert Consensus 2013 have classified breast carcinoma into luminal A, luminal B, HER2+, and triple-negative, depending on the expression of ER, PgR, HER2, and Ki-67. Research on intrinsic molecular subtypes of breast carcinoma in Indonesia, however, are rarely conducted, which then triggers the intention to conduct this study. Methods: In this work, a retrospective study was conducted on 92 formalin-fixed paraffin-embedded samples of invasive ductal breast carcinoma patients. These samples were from patients at Abdul Wahab Sjahranie County General Hospital Samarinda, East Kalimantan, Indonesia, in 2016. Next, immunohistochemical staining using anti-ER, $P g R, H E R 2$, and $\mathrm{Ki}-67$ antibodies was applied to classify intrinsic molecular subtypes. Then, an association between clinical and immunohistochemical factors with intrinsic molecular subtypes of breast carcinoma were analyzed using Chi-square test. Results: Looking at results of the retrospective study, luminal B was discovered as the most common intrinsic molecular subtypes of breast carcinoma (42.39\%) in East Kalimantan, Indonesia. The next ranks of breast carcinoma subtypes in the region included HER $+(39.13 \%)$, triple-negative $(10.87 \%)$, and luminal A $(7.61 \%)$. In fact, there was a significant association between age $(\mathrm{p}=0.019)$ with intrinsic molecular subtypes of breast carcinoma. Conclusion: The study found luminal B as the most common intrinsic molecular subtypes of Indonesian breast carcinoma in the region under investigation. In the future, the higher positivity rate of luminal B in breast carcinoma patients compared to prior studies would require further investigations.
\end{abstract}

Keywords: Luminal B- intrinsic molecular subtypes- breast carcinoma

Asian Pac J Cancer Prev, 20 (8), 2247-2252

\section{Introduction}

Currently, breast carcinoma has been recognized as the world's most commonly occuring cancer type. It has been estimated to cause deaths of over 500,000 women annually all around the world. Besides, estimated 1.7 million cases of breast carcinoma are diagnosed every year (DeSantis et al., 2014). In fact, almost a quarter of breast carcinoma are diagnosed in Asia-Pacific regions, in which Indonesia is in third place. Among globally estimated 500,000 deaths of females annually, about $22 \%$ deaths occur throughout the Asia-Pacific region. Ranking third in the region, Indonesia accounted for $17 \%$ of breast carcinoma deaths in second place after China. Breast carcinoma has also estimated to account for $9 \%$ of cancer-related deaths among females in the Asia-Pacific, ranking fourth behind lung, liver, and stomach cancers (Youlden et al., 2014).
In current advances, breast carcinoma has been posited a heterogeneous disease. In other words, it has no longer been considered as a single and standalone one. Breast carcinoma subtypes can be determined by applying immunohistochemistry methods. These subtypes have been known to vary in terms of risk factors, natural histories, and responses to therapies (Goldhirsch et al., 2011). In 2013, St. Gallen International Expert Consensus on the Primary Therapy of Early Breast Cancer has determined a classification of intrinsic molecular subtypes of breast carcinoma based of their clinicopathologic surrogate definitions. The classification includes luminal A, luminal B, HER2+, and triple-negative (Goldhirsch et al., 2013).

In general, each subtypes group is characterized as having different prognosis and response to therapy (Tao et al., 2015). Luminal A particularly has a smaller tumor

${ }^{1}$ Department of Community Medicine, ${ }^{4}$ Medical Doctor Program, Faculty of Medicine, ${ }^{2}$ Research Center of MCTrops, Mulawarman University, ${ }^{3}$ Department of Pathological Anatomy, Abdul Wahab Sjahranie General County Hospital, Samarinda, East Kalimantan, Indonesia. *For Correspondence: s.paramita@fk.unmul.ac.id 
size, the best prognosis and the lowest recurrence rate than other subtypes. Technically, it is characterized by higher levels of $E R$ and lower levels of the proliferation-related genes, including $\mathrm{Ki}-67$. In practices, recommendations for luminal A are mainly based on endocrine therapy (Prat et al., 2013). Furthermore, Luminal B has an aggressive phenotype and worse prognosis compared to luminal A. It is characterized by higher levels of growth factor receptor such as $H E R 2$, which activates signaling pathways (Yan et al., 2015). In details, HER2+ subtypes have a poor prognosis, and characterized by high proliferation rates. Therapy for luminal B subtype includes the uses of anti-HER2 such as Trastuzumab. In terms of recommended therapies, luminal B delivers its best responses to neoadjuvant chemotherapy (Asif et al., 2016). Moreover, the triple-negative subtype has been recognized to show the most aggressive behavior with the worst outcome. This subtype is not responding well to either endocrine or adjuvant chemotherapy. Requiring a specific-targeted therapy, chemotherapy is hence stated as the only choice of treatment. Then, these subtypes have been actively studied by various researchers (Keam et al., 2011).

In the literature, prior studies on intrinsic molecular subtypes of breast carcinoma in Indonesia have been focusing on ER, $P g R, H E R 2$, and $\mathrm{Ki}-67$ markers. They are, however, largely produce different results (Prihantono et al., 2017a, 2017b; Rahmawati et al., 2018; Widodo et al., 2017, 2014).

\section{Materials and Methods}

\section{Patients}

A retrospective study was performed at Abdul Wahab Sjahranie County General Hospital, Samarinda, East Kalimantan, Indonesia, involving samples from patients between January-December 2016. An ethical clearance was obtained from the Ethical Review Committee of the Faculty of Medicine, Mulawarman University, Samarinda, Indonesia (49/KEPK-FK/VI/2017) before conducting the study. In addition to ER, PgR and HER2 status and Ki67 index, clinical information used in this included ages at diagnosis, tumor sizes, and histological grades. After data gathering, there were 92 cases during the period under investigation. These cases had formalin-fixed paraffin-embedded blocks available for immunohistochemical staining.

\section{Immunohistochemical}

In this study, immunohistochemical staining method was performed on formalin-fixed paraffin-embedded blocks. Technically, a section of blocks was stained with primary antibodies for $E R, P g R, H E R 2$, and $K i-67$ (all from Leica Biosystem, Newcastle, UK). An automated immunohistochemical staining was conducted and assessed in Leica BOND MAX (Leica Biosystem, Newcastle, UK). Tumors with $\geq 1 \%$ positively nuclear-stained cells were considered positive for both ER and PgR expression (Hammond et al., 2010). Besides, HER2 positive was scored if the staining occured for $>10 \%$ of tumor cells
(Wolff et al., 2013). Then, tumors containing $\geq 14 \%$ of nuclear $\mathrm{Ki}-67$ expression was considered as having a high Ki-67 rate (Cheang et al., 2009).

\section{Definition of intrinsic molecular subtypes}

According to the 2013 St. Gallen Consensus, samples could be distinguished based on their ER, PgR, HER2, and $K i-67$ expressions. Technically speaking, samples were stated as luminal A $(E R+, P g R+, H E R 2-$, and $\mathrm{Ki}-67$ low), luminal B $(E R+, P g R+$, any $H E R 2$, and any $K i-67)$, $H E R 2+(E R-, P g R$-, and HER2 over-expressed) or triple negative (ER-, PgR-, and HER2-) (Goldhirsch et al., 2013).

\section{Statistical analysis}

In this study, a chi-square test was employed to examine the association of breast carcinoma intrinsic molecular subtypes with clinical and immunohistochemical factors. The test applied values of $p<0.05$ as considerably significant. All statistical analyses were performed in PSPPIRE 1.0.1 software.

\section{Results}

\section{Characteristics of patients}

A total of 92 cases of breast carcinoma were included in this study with the following clinical information. First, the mean of patient's age was 48.29 years old (ranged between 23-83 years old), while the mean of tumor size was $5 \mathrm{~cm}$ (ranged between 1-17 cm). Besides, the majority of patient's histological grade was in the third group $(68.48 \%)$. After the immunohistochemical staining process, the $E R, P g R$, and $H E R 2$ positive expressions were

Table 1. Clinical and Immunohistochemical Characteristics of Patients

\begin{tabular}{llc}
\hline Characteristics & & \\
\hline Age (years) & Mean \pm SD & $48.29 \pm 10.7$ \\
& Min - Max & $23-83$ \\
Tumor size (cm) & Mean \pm SD & $5.00 \pm 3.1$ \\
& Min - Max & $1-17$ \\
Histological Grade & 1 & $5(5.43 \%)$ \\
& 2 & $24(29.09 \%)$ \\
& 3 & $63(68.48 \%)$ \\
Molecular Subtypes & Luminal A & $7(7.61 \%)$ \\
& Luminal B & $39(42.39 \%)$ \\
& HER2+ & $36(39.13 \%)$ \\
& Triple negative & $10(10.87 \%)$ \\
ER & Negative & $46(50 \%)$ \\
& Positive & $46(50 \%)$ \\
PgR & Negative & $47(51.09 \%)$ \\
HER2 & Positive & $45(48.91 \%)$ \\
& Negative & $39(42.39 \%)$ \\
& Positive & $53(57.61 \%)$ \\
& $<14 \%$ & $15(16.30 \%)$ \\
& $14-30 \%$ & $18(19.67 \%)$ \\
& $>30 \%$ & $59(64.13 \%)$ \\
\hline
\end{tabular}


DOI:10.31557/APJCP.2019.20.8.2247

Luminal B is the Most Common Intrinsic Molecular Subtypes of Breast Carcinoma

Table 2. Association between Clinical and Immunohistochemical Factors with Intrinsic Molecular Subtypes

\begin{tabular}{|c|c|c|c|c|c|c|c|}
\hline \multicolumn{2}{|l|}{ Characteristics } & \multirow{2}{*}{$\begin{array}{c}\text { All cases } \\
\text { n (\%) } \\
6(6.5)\end{array}$} & \multirow{2}{*}{$\begin{array}{c}\text { Luminal A } \\
\mathrm{n}(\%) \\
1(14.3)\end{array}$} & \multirow{2}{*}{$\begin{array}{c}\text { Luminal B } \\
n(\%) \\
4(10.3)\end{array}$} & \multirow{2}{*}{$\begin{array}{c}\text { HER2+ } \\
\text { n (\%) } \\
1(2.8)\end{array}$} & \multirow{2}{*}{$\begin{array}{c}\text { Triple negative } \\
\mathrm{n}(\%) \\
0(0)\end{array}$} & \multirow{2}{*}{$\begin{array}{l}\text { P value } \\
0.019 \dagger\end{array}$} \\
\hline Age & $\leq 35$ ys & & & & & & \\
\hline & $>35 \mathrm{ys}$ & $86(93.5)$ & $6(85.7)$ & $35(89.7)$ & $35(97.2)$ & $10(100)$ & \\
\hline \multirow[t]{2}{*}{ Size } & $\leq 2 \mathrm{~cm}$ & $19(20.7)$ & $2(28.6)$ & $8(20.5)$ & $7(19.4)$ & $2(20)$ & 0.978 \\
\hline & $>2 \mathrm{~cm}$ & $73(79.3)$ & $5(71.4)$ & $31(79.5)$ & $29(80.6)$ & $8(80)$ & \\
\hline \multirow[t]{2}{*}{ Grade } & 1,2 & $29(31.5)$ & $3(42.9)$ & $13(33.3)$ & $7(19.4)$ & $6(60)$ & 0.091 \\
\hline & 3 & $63(68.5)$ & $4(57.1)$ & $26(66.7)$ & $29(80.6)$ & $4(40)$ & \\
\hline \multirow[t]{2}{*}{ ER } & Negative & $46(50)$ & $0(0)$ & $0(0)$ & $36(100)$ & $10(100)$ & $0.000 \dagger$ \\
\hline & Positive & $46(50)$ & $7(100)$ & $39(100)$ & $0(0)$ & $0(0)$ & \\
\hline \multirow[t]{2}{*}{ PgR } & Negative & $48(52.2)$ & $0(0)$ & $3(7.7)$ & $36(100)$ & $9(90)$ & $0.000 \dagger$ \\
\hline & Positive & $44(47.8)$ & $7(100)$ & $36(92.3)$ & $0(0)$ & $1(10)$ & \\
\hline \multirow[t]{2}{*}{ HER2 } & Negative & $39(42.4)$ & $7(100)$ & $22(56.4)$ & $0(0)$ & $10(100)$ & $0.000 \dagger$ \\
\hline & Positve & $53(57.6)$ & $0(0)$ & $17(43.6)$ & $36(100)$ & $0(0)$ & \\
\hline \multirow[t]{2}{*}{ Ki-67 } & Low & $15(16.3)$ & $7(100)$ & $1(2.6)$ & $4(11.1)$ & $3(30)$ & $0.000 \dagger$ \\
\hline & High & $77(83.7)$ & $0(0)$ & $38(97.4)$ & $32(88.9)$ & $7(70)$ & \\
\hline
\end{tabular}

†Chi-square, $\mathrm{p}$ value $<0.05$

discovered to be $50 \%, 48.91 \%$, and $57.61 \%$, respectively. In particular, the majority of $\mathrm{Ki}-67$ expressions were in the high group (64.13\%). Among observed samples, luminal B comprised the most common intrinsic molecular subtypes in the population $(42.39 \%)$, which was then followed by HER $+(39.13 \%)$, luminal A $(10.87 \%)$, and triplenegative $(7.61 \%)$. Table 1 presents the characteristics of observed patients with breast carcinoma.

Association between clinical and immunohistochemical factors with intrinsic molecular subtypes

Looking at the chi-square test, a significant result $(p=0.019)$ was revealed for the association of between age with intrinsic molecular subtypes of breast carcinoma. In this study, luminal B was discovered as the most commonly occuring subtypes in patients aged $\leq 35$ years, while $H E R 2$ + was most common subtypes in older patients. Table 2 exhibits the association between clinical and immunohistochemical factors with intrinsic molecular subtypes of breast carcinoma.

\section{Discussion}

This research had evaluated the distribution of intrinsic molecular subtypes of breast carcinoma and studied their association and correlation with clinical and immunohistochemical factors. In this study, samples under investigation included 92 breast carcinoma patients. The mean age of these samples was 48.29 years old (ranged between 23-83 years old), which was in fact similar to prior study in Makassar, Indonesia, with 46 years old as the average age at diagnosis (Prihantono et al., 2017a). Besides, studies in Malaysia and Indonesia indicated breast carcinoma to present at a younger age for Indonesian women compared to Malaysian women. Ethnical and genetic differences might highlight these results (Ng et al., 2011).

Furthermore, the mean of tumor size in this study was
$5 \mathrm{~cm}$ (ranged between 1-17 cm). In fact, similar results were discovered by other studies in Indonesia. It confirmed a behavior among breast carcinoma patients in Indonesia, who, in most cases, reported their health condition when their tumor had already become larger in size (Widodo et al., 2017). On the other hand, the majority of patient's histological grade in this research was in the high group $(68.48 \%)$. Different results were revealed by other studies in Indonesia, in which moderate differentiation was the most common grade compared to high and low group. In practices, histological grading was the predictive and prognostic factor of breast carcinoma (Rahmawati et al., 2018; Widodo et al., 2014).

Furthermore, positive $E R, P g R$, and HER 2 expression were discovered at $50 \%, 48.91 \%$, and $76.09 \%$, respectively. It was parallel with the high frequency of positive HER2 expressions (56.6\%) found in prior study conducted in Makassar, Indonesia (Prihantono et al., 2017b). Besides, the majority of $K i-67$ expressions were in the high group (83.7\%), which was similar to previous results of the study in Makassar with $\mathrm{Ki}-67$ positive index at about $54.2 \%$ (Prihantono et al., 2017a).

Next, this study discovered luminal B to comprise the most commonly occuring intrinsic molecular subtypes among observed population $(42.39 \%)$. After luminal $\mathrm{B}$, the following ranks were HER2+ $(39.13 \%)$, luminal A $(6.52 \%)$, and triple-negative (4.36\%). The result was particularly similar to other studies that focused on cases in Southeast Asia regions. Prior research in Vietnam, for example, revealed a relatively high percentage of luminal B subtype (56.5\%) (Thang et al., 2015). In another research, the mean percentage of luminal B patients discovered in Myanmar was $46.2 \%$, which was considerably higher than other subtypes (San et al., 2017). Results in Southeast Asia regions were also similar to studies conducted on breast carcinoma cases in other Asia regions. Outside Asia, e.g. in Morocco, luminal B was also discovered as the most frequently occuring molecular subtype of breast cancer 
(Fatemi et al., 2012).

In terms of clinical information, this study revealed a significant association between patients' age with intrinsic molecular subtypes of breast carcinoma. Apparently, luminal B was the most common subtype in patients aged $\leq 35$ years, while HER $2+$ was the most common subtype in older patients. Results as such indicated younger patients to generally have the worst prognosis. Similar results were discovered by a previous study conducted in Turkey, in which older age was found to act as a risk factor for HER2+ overexpressing subtype. Compared to other subtypes, luminal B cases were more likely to occur on patients with younger age at diagnosis (Turkoz et al., 2013).

However, of this study differed from previous reports in other provinces in Indonesia, which found luminal A as the most frequently occuring subtype (Rahmawati et al., 2018; Widodo et al., 2017, 2014). Also, it was different from prior research in Malaysia and Indonesia, which showed tumors suffered by Indonesian women to more likely be $H E R 2+$ compared to Malaysian women $(\mathrm{Ng}$ et al., 2011). The higher HER2 positivity rate in Indonesia has been previously reported about $64.2 \%$ (Aryandono et al., 2006).

According to the 2013 St. Gallen Consensus, luminal $\mathrm{B}$ could be further distinguished by looking at $E R, P g R$, $H E R 2$, and $K i-67$ expressions. The classification of luminal B included luminal B-like HER2- (ER+, HER2-, and at least one of $K i-67$ high or $P g R$-) and luminal B-like $H E R 2+(E R+$, any $P g R, H E R 2$ over-expressed, and any Ki-67) (Goldhirsch et al., 2013). Practically, estrogen and progesterone receptors (ER and $P g R$ ) and $H E R 2$ had been stated as having critical influences on the management of breast cancer. Estrogen had particularly been posited as an important mitogen exerting its activity by being bound to its estrogen receptor $(E R)$, which found in almost $80 \%$ of breast cancer cases (Azizun-Nisa et al., 2008). Meanwhile, $\mathrm{PgR}$ had been recognized as a surrogate marker of a functional $E R$, which would be valuable in predicting the behavior of breast carcinoma. It had been discovered in almost $70 \%$ invasive breast carcinomas with a higher positivity in postmenopausal women. The presence of hormone receptors $(E R$ and $P g R)$ in the tumor tissues were then stated as being well correlated with expected responses to chemotherapy (Shaikh et al., 2016).

Furthermore, HER 2 had been recognized as a proto-oncogene located on chromosome $17 \mathrm{q}$. Besides, it encoded a $185 \mathrm{kDa}$ transmembrane phosphoglycoprotein with tyrosine kinase activity, which had mainly been found at the cell surface of tumor cells. It is amplified and HER 2 overexpressed in almost $25 \%$ of invasive breast carcinoma with associated poor prognosis (Tan et al., 2009). Another research in Mexico found HER2 marker to considerably be associated with a number of pregnancies (Cindy et al., 2015). Meanwhile, prior research in Malaysia discovered women with HER2+ tumors to significantly and more likely be parous than those with luminal A tumors (Devi et al., 2012). Then, a previous work conducted in East Kalimantan, Indonesia, had also associated risk factors of other cancer types with a number of pregnancies (Paramita et al., 2010).

In general, the limitation of this study included additional focuses on other factors such as genetic background, while ethnical and risk factors were also not evaluated. Further investigations of those factors would hence be necessary. Theoretically speaking, extensive distributions of intrinsic molecular subtypes among worldwide population suggested the critical role of human races or ethnicities in distinguishing breast carcinoma subtypes.

As the conclusion, this study discovered the frequency of intrinsic molecular subtypes of breast carcinoma to vary among different human populations. In particular, the current work had confirmed luminal B as the most commonly occuring intrinsic molecular subtypes of breast carcinoma in East Kalimantan, Indonesia. In terms of clinical information, age was found to be associated with intrinsic molecular subtypes of breast carcinoma. Therefore, the higher luminal B positivity rates in Indonesian patients would require a further study. Findings of this study highlighted an urgent need for a set of comprehensive breast carcinoma awareness programs particularly in East Kalimantan, Indonesia. It should particularly be designed to encourage women to be aware of their breast carcinoma-related health conditions at earlier stages.

\section{Acknowledgments}

Acknowledgments to the Faculty of Medicine, Mulawarman University, Samarinda, Indonesia, for financing this research, as part of the implementation of Research Grant of Mulawarman University year of 2017. All procedures followed were following the ethical standards from the Ethical Review Committee of the Faculty of Medicine, Mulawarman University, Samarinda, Indonesia. The authors declare that they have no competing interests.

\section{Funding Statement}

This research was funding by Research Grant of Mulawarman University, Samarinda, Indonesia.

\section{Statement conflict of Interest}

The authors do not have any conflicts of interest to declare.

\section{References}

Al Tamimi DM, Shawarby MA, Ahmed A, et al (2010). Protein expression profile and prevalence pattern of the molecular classes of breast cancer - a Saudi population based study. BMC Cancer, 10, 223.

Aryandono T, Harijadi H, Soeripto S (2006). Breast cancer in young women: Prognostic factors and clinicopathological features. Asian Pac J Cancer Prev, 7, 451-4.

Asif HM, Sultana S, Ahmed S, et al (2016). HER-2 positive breast cancer - a mini-review. Asian Pac J Cancer Prev, 17, 1609-15.

Azizun-Nisa A, Bhurgri Y, Raza F, Kayani N (2008). Comparison of ER, PR and HER-2/neu (C-erb B 2) reactivity pattern with histologic grade, tumor size and lymph node status in breast 
cancer. Asian Pac J Cancer Prev, 9, 553-6.

Caldarella A, Buzzoni C, Crocetti E, et al (2013). Invasive breast cancer: a significant correlation between histological types and molecular subgroups. J Cancer Res Clin Oncol, 139, 617-23.

Cheang MCU, Chia SK, Voduc D, et al (2009). Ki67 Index, HER2 status, and prognosis of patients with Luminal B breast cancer. J Natl Cancer Inst, 101, 736-50.

Chuangsuwanich T, Pongpruttipan T, Ocharoenrat P, et al (2014). Clinicopathologic features of breast carcinomas classified by biomarkers and correlation with microvessel density and VEGF expression: A study from Thailand. Asian Pac J Cancer Prev, 15, 1187-92.

Cindy B, Paloma DG-M, Alfredo C-A, et al (2015). Association of histopathological markers with clinico- pathological factors in Mexican women with breast cancer. Asian Pac J Cancer Prev, 16, 8397-403.

Desantis C, Ma J, Bryan L, et al (2014). Breast cancer statistics, 2013. CA Cancer J Clin, 64, 52-62.

Devi CRB, Tang TS, Corbex M (2012). Incidence and risk factors for breast cancer subtypes in three distinct South-East Asian ethnic groups: Chinese, Malay and natives of Sarawak, Malaysia. Int J Cancer, 131, 2869-77.

Doval DC, Sharma A, Sinha R, et al (2015). Immunohistochemical profile of breast cancer patients at a tertiary care Hospital in New Delhi, India. Asian Pac J Cancer Prev, 16, 4959-64.

Fatemi, HE, Chahbouni S, Jayi S, et al (2012). Luminal B tumors are the most frequent molecular subtype in breast cancer of North African women: an immunohistochemical profile study from Morocco. Diagn Pathol, 7, 170.

Goldhirsch A, Winer EP, Coates AS, et al (2013). Personalizing the treatment of women with early breast cancer: highlights of the St Gallen International Expert Consensus on the Primary Therapy of Early Breast Cancer 2013. Ann Oncol, 24, 2206-23.

Goldhirsch A, Wood WC, Coates AS, et al (2011). Strategies for subtypes-dealing with the diversity of breast cancer: highlights of the St Gallen International Expert Consensus on the Primary Therapy of Early Breast Cancer 2011. Ann Oncol, 2, 1736-47.

Hammond MEH, Hayes DF, Dowsett M, et al (2010). American society of clinical oncology/college of American pathologists guideline recommendations for immunohistochemical testing of estrogen and progesterone receptors in breast cancer. Arch Pathol Lab Med, 134, 48-72.

Hennigs A, Riedel F, Gondos A, et al (2016). Prognosis of breast cancer molecular subtypes in routine clinical care: A large prospective cohort study. BMC Cancer, 16, 734.

Howlader N, Altekruse SF, Li CI, et al (2014). US incidence of breast cancer subtypes defined by joint hormone receptor and HER 2 status. J Natl Cancer Inst, 106, dju055.

Keam B, Im SA, Lee KH, et al (2011). Ki-67 can be used for further classification of triple negative breast cancer into two subtypes with different response and prognosis. Breast Cancer Res, 13, R22.

Keyhani E, Muhammadnejad A, Karimlou M (2012). Prevalence of HER-2-positive invasive breast cancer: A systematic review from Iran. Asian Pac J Cancer Prev, 13, 5477-82.

Munjal K, Ambaye A, Evans MF, et al (2009). Immunohistochemical analysis of ER, PR, Her2 and CK5/6 in infiltrative breast carcinomas in Indian patients. Asian Pac J Cancer Prev, 10, 773-8.

$\mathrm{Ng} \mathrm{CH}$, Pathy NB, Taib NA, et al (2011). Comparison of breast cancer in Indonesia and Malaysia - A clinico-pathological study between Dharmais cancer centre Jakarta and University Malaya Medical Centre, Kuala Lumpur. Asian Pac J Cancer Prev, 12, 2943-6.
Paramita S, Soewarto S, Widodo MA, et al (2010). High parity and hormonal contraception use as risk factors for cervical cancer in East Kalimantan. Med J Indones, 19, 268-72.

Prat A, Cheang MCU, Martín M, et al (2013). Prognostic significance of progesterone receptor-positive tumor cells within immunohistochemically defined Luminal A breast cancer. J Clin Oncol, 31, 203-9.

Prihantono P, Hatta M, Binekada C, et al (2017). Ki-67 expression by immunohistochemistry and quantitative real-time polymerase chain reaction as predictor of clinical response to neoadjuvant chemotherapy in locally advanced breast cancer. J Oncol, 2017, ID 6209849.

Prihantono P, Sampepajung D, Islam AA, et al (2017). Profile of mRNA expression of Ki-67 in breast cancer patients pre- and post- chemotherapy. Am J Clin Exp Med, 5, 10-4.

Rahmawati Y, Setyawati Y, Widodo I, et al (2018). Molecular subtypes of Indonesian breast carcinomas - Lack of association with patient age and tumor size. Asian Pac J Cancer Prev, 19, 161-6.

San TH, Fujisawa M, Fushimi S, et al (2017). Molecular subtypes of breast cancers from Myanmar women: A study of 91 cases at two pathology centers. Asian Pac J Cancer Prev, 18, 1617-21.

Shaikh F, Jamal Q, Baig S, Hadi NI, Majeed N (2016). Correlation of hormone receptor and HER-2/neu expression with clinicopathologic parameters in primary breast tumors. Asian Pac J Cancer Prev, 17, 3363-7.

Tan G-H, Choo W-Y, Taib NA, et al (2009). Factors associated with HER2 overexpression in breast cancer: Experience in an Asian developing country. Asian Pac J Cancer Prev, 10, 837-40.

Tao ZQ, Shi A, Lu C, et al (2015). Breast cancer: Epidemiology and etiology. Cell Biochem Biophys, 72, 333-8.

Thang VH, Skoog L, Duc NB, et al (2015). Cell proliferation measured by Ki67 staining and correlation to clinicopathological parameters in operable breast carcinomas from Vietnamese and Swedish patients. J Anal Oncol, 4, 58-68.

Turkoz FP, Solak M, Petekkaya I, et al (2013). Association between common risk factors and molecular subtypes in breast cancer patients. Breast J, 22, 344-50.

Wang W-J, Lei Y-Y, Mei J-H, et al (2015). Recent progress in HER2 associated breast cancer. Asian Pac J Cancer Prev, 16, 2591-600.

Widodo I, Dwianingsih EK, Anwar SL, et al (2017). Prognostic value of clinicopathological factors for Indonesian breast carcinomas of different molecular subtypes. Asian Pac J Cancer Prev, 18, 1251-6.

Widodo I, Dwianingsih EK, Triningsih E, et al (2014). Clinicopathological features of Indonesian breast cancers with different molecular subtypes. Asian Pac J Cancer Prev, 15, 6109-13.

Wolff AC, Hammond ME, Hicks DG, et al (2013). Recommendations for human epidermal growth factor receptor 2 testing in breast cancer: American Society of Clinical Oncology/College of American Pathologists clinical practice guideline update. J Clin Oncol, 31, 3997-4013.

Yan J, Liu X-L, Han L-Z, et al (2015). Relation between Ki-67, ER, PR, Her2/neu, p21, EGFR, and TOP II- $\alpha$ expression in invasive ductal breast cancer patients and correlations with prognosis. Asian Pac J Cancer Prev, 16, 823-9.

Yanagawa M, Ikemot K, Kawauchi S, et al (2012). Luminal A and luminal B (HER2 negative) subtypes of breast cancer consist of a mixture of tumors with different genotype. $B M C$ Res Notes, 5, 376.

Youlden DR, Cramb SM, Yip CH, et al (2014). Incidence and mortality of female breast cancer in the Asia-Pacific region. 
Swandari Paramita et al

Cancer Biol Med, 11, 101-15.

Zhu X, Ying J, Wang F, et al (2014). Estrogen receptor, progesterone receptor, and human epidermal growth factor receptor 2 status in invasive breast cancer: a 3,198 cases study at National Cancer Center, China. Breast Cancer Res Treat, 147, 551-5.

\section{(ब) $(1)$}

This work is licensed under a Creative Commons AttributionNon Commercial 4.0 International License. 